\title{
The Present Situations of Engineering Education and Accreditation System in Korea
}

\author{
Sung-gun Kang*, Tae-Cheon Rho**, Seung-Yeon Hahm***, Cheong-Sig Kim**** \\ *Professor of Hanyang University, Hangdang-dong, Seongdong-gu, Seoul, 133-791, Korea: sgkang@hanyang.ac.kr \\ President of Korean Society for Engineering Education \\ ** Professor of Chungnam National University, Gung-dong, Yusung-gu, Daejeon-city, 305-764, Korea: tcrho@cnu.ac.kr \\ President of Korean Institute of Industrial Educators \\ ***Ph.D. Associate Research Fellow of Korea Institute of Curriculum \& Evaluation, 25-1, \\ Samcheong-dong, Jongro-gu, Seoul, 110-230, Korea: syhahm@kice.re.kr \\ **** Ph.D. Research Fellow of Engineering Education Research Center, College of Engineering Science, \\ Hanyang University. 1271 Sa 1-dong, Sangnok-gu, Ansan Kyungki-do 426-791, Korea: kjs@hanyang.ac.kr
}

\begin{abstract}
The Accreditation Board for Engineering Education in Korea was founded in 1999 and the first engineering education programs were accredited in 2001. The purpose of accreditation was to attract outstanding students to engineering colleges as well as to raise highly qualified engineers who would be recognized internationally. The accreditation of engineering education has expanded as more and more colleges and programs are asking to participate in this accreditation program. This study examines the current position and future direction of Korean engineering education To develop further, engineering education in Korea requires more support to attract outstanding students to engineering colleges and to provide high quality education. Also, Korea should become a member of Washington Accord to be recognized as international level of engineering education as well as active cooperation from engineering related organizations, institutions, and businesses.
\end{abstract}

Keywords: engineering education, accreditation program

\section{Introduction}

The $21^{\text {st }}$ century is a knowledge information-oriented society. In this type of society, educating people with superior scientific technique is an absolute necessity to secure competitiveness and to develop the nation. While national competitive power in the past was decided based on production factors such as natural resources, land, and capital, human capital with innovative research techniques are the basis of power in $21^{\text {st }}$ century. Therefore, the quality of engineers that a society produces is a factor in deciding the future of a nation.

Nevertheless, as Korea has suffered economic crisis, including Asian financial crisis, superior high school graduates tend to apply to Chinese medicine or medicine programs and avoid engineering programs relatively thereby reducing the number of excellent students applying to engineering colleges. This has caused a serious decline in scientific skills. This is a vicious circle caused by decline in the status in society as engineers who were the driving force of economic growth of Korea in the past which resulted in avoidance of engineering and science programs. This phenomenon is also happening in developed countries and many systems and policies are being made to overcome this problem.

In case of Korea, the Accreditation Board for Engineering Education of Korea was established in 1999 and started to accredit engineering education programs in 2001 (Ham Seung-yeon, 2005). Also, Korea became an associate member of the Washington Accord in 2005, which provided a chance for engineering students in accredited institutions in Korea to be recognized at the same level of qualification internationally.

This study analyzes the current situation in engineering education and accreditation of engineering education seeks solutions for the problems of Korean engineering education based on basic data on Korean engineering education.

\section{The Current state of Engineering Education of Korea}

There are 173 universities ${ }^{1)}$ including 24 national, 2 public, and 147 private universities in Korea as indicated in $<$ Table $1>$ and $<$ Figure $1>$ in the base year of 2005. A total of 1,859,639 students ${ }^{2)}$ were registered in four-year system general universities including 379,254 in national universities, 21,414 in public universities, and 1,458,971 in private universities as indicated in $<$ Table $2>$ and $<$ Figure $2>$. Among these students, $21.5 \%$ of the total are national and public university students and $78.5 \%$ of them are private university students, indicating that general university education depends highly on private education.

\footnotetext{
1) Satellite campuses, education universities, industrial universities, technological universities, and online universities are excluded.

${ }^{2)}$ It indicates the number of students currently registered in university and education universities, industrial universities, technological universities, and online universities are excluded.
} 
$<$ Table 1> Public and Private Universities in 2005 (unit: university) (unit: university)

\begin{tabular}{|c|c|c|c|c|}
\hline year & total & national university & public university & private university \\
\hline 2005 & 173 & 24 & 2 & 147 \\
\hline
\end{tabular}

Data: Reorganized Education Statistics Analysis Data (2005), p.11

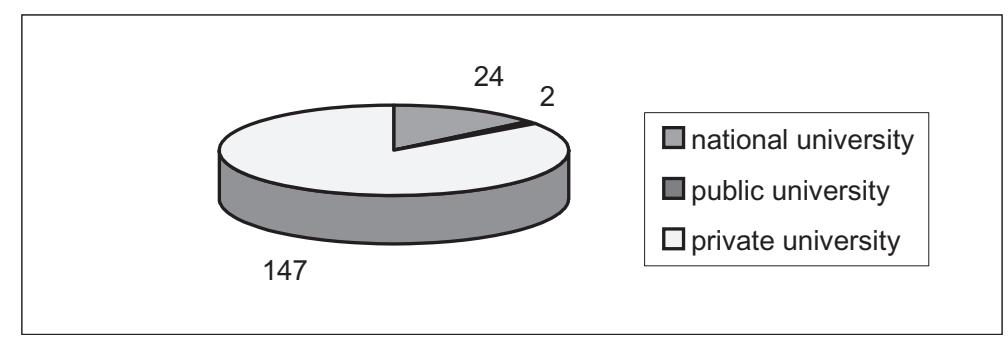

$<$ Figure $1>$ Number of universities in 2005

$<$ Table $2>$ Number of university students in 2005

\begin{tabular}{|c|c|c|c|c|c|c|c|c|}
\hline \multirow{2}{*}{ year } & \multicolumn{2}{|c|}{ total } & \multicolumn{2}{c|}{ national university } & \multicolumn{2}{c|}{ public university } & \multicolumn{2}{c|}{ private university } \\
\cline { 2 - 9 } & subtotal & female & Subtotal & female & subtotal & female & subtotal & female \\
\hline 2005 & $1,859,639$ & 684,238 & 379,254 & 128,463 & 21,414 & 5,888 & $1,458,971$ & 549,887 \\
\hline
\end{tabular}

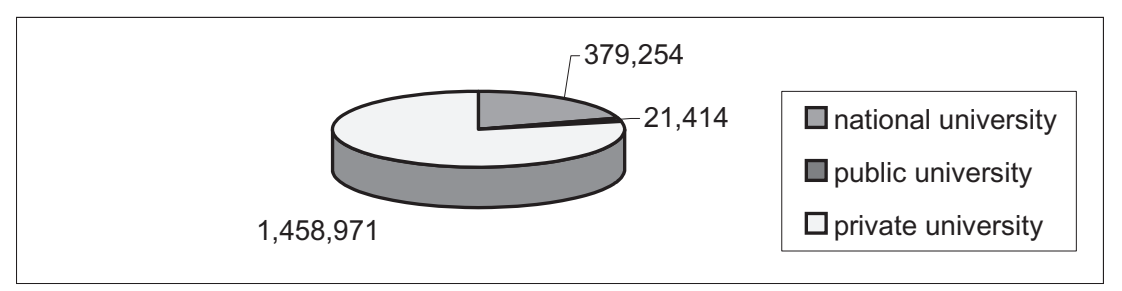

$<$ Figure 2>Number of university students in 2005

Considering the ratio of students according to programs in universities, the number of students in engineering programs has declined after a steady increase until 2002 and the ratio of female students in engineering programs has also shown the same pattern as can be seen in $<$ Table $3>$. The ratio of students in science programs shows both an increase and a decrease while medicine program shows decrease or constant level after 1990.

$<$ Table $3>$ Ratio of students in each major program in each year

\begin{tabular}{|c|c|c|c|c|c|c|c|c|}
\hline \multirow{2}{*}{ year } & \multicolumn{2}{|c|}{ art } & \multicolumn{2}{c|}{ Engineering } & \multicolumn{2}{c|}{ science } & \multicolumn{2}{c|}{ medicine } \\
\cline { 2 - 9 } & total & female & total & female & total & female & total & female \\
\hline 1970 & 12.1 & 18.6 & 22.8 & 0.9 & 17.7 & 20.6 & 8.8 & 13.5 \\
\hline 1990 & 15.0 & 24.5 & 23.0 & 5.0 & 17.3 & 22.1 & 3.9 & 4.8 \\
\hline 2000 & 13.5 & 21.2 & 30.2 & 10.7 & 13.5 & 16.3 & 3.7 & 5.0 \\
\hline 2001 & 13.4 & 20.9 & 30.5 & 11.3 & 12.9 & 15.6 & 3.6 & 4.8 \\
\hline 2002 & 13.5 & 21.1 & 31.1 & 12.1 & 11.8 & 14.2 & 3.7 & 5.0 \\
\hline 2003 & 13.9 & 21.7 & 29.2 & 10.5 & 13.1 & 15.3 & 3.6 & 4.9 \\
\hline 2004 & 13.7 & 21.4 & 28.6 & 10.1 & 12.9 & 15.1 & 3.5 & 4.8 \\
\hline 2005 & 13.5 & 21.0 & 27.9 & 9.7 & 12.6 & 14.9 & 3.4 & 4.8 \\
\hline
\end{tabular}

The employment of engineering program graduates in 2005 is shown in $<$ Table $4>.58 .5 \%$ of total graduates gained employment and $18.4 \%$ of them were female students. Of the employed students $44.6 \%$ were from fields of computer and communications engineering. And $20.8 \%$ of those who acquired a national certificate were female students. 
$<$ Table 4> Employment of engineering program graduates

\begin{tabular}{|c|c|c|c|c|c|c|c|}
\hline \multirow{3}{*}{ Classification } & \multicolumn{5}{|c|}{ Graduate status } & \multirow{2}{*}{\multicolumn{2}{|c|}{ national certificate acquirers }} \\
\hline & \multicolumn{2}{|c|}{ Graduates } & \multicolumn{2}{|c|}{ employed } & \multirow{2}{*}{$\begin{array}{c}\text { ones in the army } \\
\text { subtotal }\end{array}$} & & \\
\hline & subtotal & female & subtotal & female & & subtotal & female \\
\hline Architecture & 7,542 & 2,131 & 4,277 & 1,117 & 84 & 1,660 & 352 \\
\hline construction and city planning & 6,121 & 837 & 3,595 & 429 & 50 & 1,716 & 197 \\
\hline transportation & 3,043 & 381 & 1,853 & 189 & 71 & 694 & 64 \\
\hline machinery and metal & 7,960 & 386 & 4,905 & 207 & 74 & 824 & 45 \\
\hline electricity and electronics & 11,021 & 1,253 & 6,439 & 696 & 122 & 1,530 & 232 \\
\hline precision and energy & 422 & 91 & 215 & 51 & 5 & 54 & 14 \\
\hline matter and material & 4,516 & 973 & 2,463 & 509 & 29 & 461 & 111 \\
\hline computer and communication & 19,981 & 5,690 & 11,668 & 3,219 & 189 & 4,738 & 1,400 \\
\hline industry & 3,070 & 496 & 1,885 & 279 & 25 & 539 & 81 \\
\hline chemistry engineering & 3,671 & 1,083 & 2,002 & 515 & 21 & 360 & 124 \\
\hline others & 2,072 & 401 & 1,319 & 243 & 9 & 532 & 100 \\
\hline total & 69,419 & 13,722 & 40,621 & 7,454 & 679 & 13,108 & 2,720 \\
\hline
\end{tabular}

\section{The Present Position of Korean Engineering Education Accreditation System}

Although this phenomenon of avoiding science and engineering programs and a lack of human resources needed by industry is a widespread problem internationally, Korea has an even more serious problem of having a gap of core brains despite the number of engineers we are producing. Consequently, many organizations that are related to engineering such as businesses, academics, and research centers are adapting engineering education accreditation systems to improve the quality of engineering colleges.

The purpose of the system is to improve the abilities of engineering graduates and the educational environment by supplementing the insufficiencies and improving student ability based on verification of each program in engineering colleges by specialists from both business and academics. The following are the specific purposes of this accreditation system.

In detail 1) engineering graduates are guaranteed to be placed effectively in a real job situation after finishing an accreditation program 2) the system verifies if the education institution and detailed engineering education program corresponds to the accreditation standard 3) it encourages new and innovative methods in engineering education, provides guidelines for engineering education programs, responds to inquiries, and 4) it contributes to industry and society to promote the development of engineering education and produces engineers with skills that society and industry need.

$<$ Table $5>$ The purpose of the Korean engineering education accreditation system

The purpose of Korean engineering education accreditation system

To guarantee the graduates from accredited engineering program are ready for actual engineering business practice

To promote engineering education

To inspire new and creative approach to engineering education

To announce accredited programs to the society

Since 1999 when the engineering program accreditation system started, more and more universities and programs apply to be accredited each year. In 2001 when the accreditation system started, there were only two universities and 11 programs that were accredited. After four years, there were seven universities and 40 programs accredited in 2005. Considering this increasing number of applicants for the accreditation system, it is expected that there will be 30 universities and 130 programs in this system.

This means that the system itself is proving to be effective and government policy that gives preferential treatment to professors from the accredited programs when hired as a manager of policy assignment supported by the government.It is expected that more and more programs will be accredited since there is an Engineering Accreditation Commission (EAC) and an Computer Accreditation Commission (CAC) at ABEEK.

$<$ Table $6>$ Increase in number of participants in the accreditation program

\begin{tabular}{|l|c|c|c|c|c|c|}
\hline \multicolumn{1}{|c|}{ year } & 2001 & 2002 & 2003 & 2004 & 2005 & 2006 \\
\hline Number of participating universities & 2 & 3 & 4 & 6 & 7 & 30 \\
\hline Nnumber of accredited programs & 11 & 17 & 29 & 32 & 40 & 130 \\
\hline
\end{tabular}




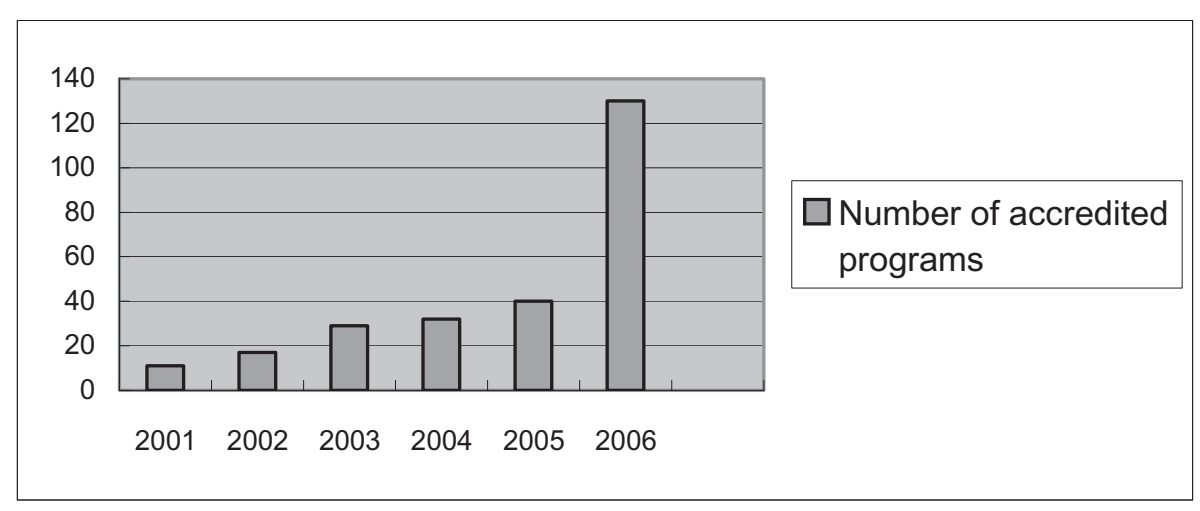

$<$ Figure $3>$ Increase in university participants in each year

$<$ Figure 3> shows that Electric and electronic engineering have the most number of accredited programs as of 2005 followed by mechanical, construction, chemistry, engineering, and architecture. Due to the number of IT related fields, accreditation was most common in departments such as computer and electronic engineering. Consequently, ABEEK established a separate business unit for computer related accreditation to accredit computer related programs in 2004.

Although there are various features in Korean engineering education accreditation, the biggest characteristic is its circular engineering education model which is the same asother developed countries. A circular engineering education model means that engineering education should be responsive to stakeholders by responding to questionnaire responses from current students, graduates, and industries about the curriculum at least yearly. This is beyond the existing knowledge-focused curriculum and is a result of increased interest and participation by stakeholders who are changing constantly. Especially, by adapting to industry requests more actively more qualified graduates can be produced. Therefore, the biggest distinction of the Korean engineering education accreditation program is making engineering education programs change into new ones after about three to four years.

Besides this, it emphasizes planning education and forces the curriculum to have a certain amount of planning education. Also, the system collects the students' portfolios and allows the students to carry them as a part of curriculum improvement, which is a very distinctive characteristic that only the Korean system has.

The student portfolio is managed by the student themselves. All the work produced during four years of university courses are contained on a CD and are collected by the system focusing on what they can do rather than what university they graduated from. Basic knowledge education emphasizes requirements for engineers in present society such as ethics, social responsibility, and the social impact of technology to educate future engineers to have a high quality standard rather than giving them traditional culture focused education. It also emphasizes major subjects of study by requiring twice as much practical education as before. Therefore, students are ready to work in real job situations right after they graduate. To do this, the system requires more emphasis on basic mathematics, science, and computer related credits. Especially, two semester courses in mathematics, physics, and chemistry should be taken consecutively.

Engineering education accreditation system performs the accreditation process in a free atmosphere with documented and objective data to achieve its original purpose which is to overcome oppressive and authoritative evaluation standards. This approach is effective because the difference between university and specialists improving the quality of education by consulting to specialist.

It also promotes standards so that the society, parents, and industry can support the system and verify the result.

Generally, the accreditation indices are as follows 1) it gives accreditation when the engineering education meets the general accreditation standard and the system standard 2) it does not give accreditation when the education program does not have the required education for one to become an engineer. Also, a program that does not have basic engineering education cannot be accredited even though it is a great engineering related program 3) it avoids regulated and fixed accreditation standards by adapting rigid standards and encourages real and experimental characteristic of engineering programs and 4) it reflects not only quantitative factors but also qualitative factors when accrediting.

Above all things, a program can be accredited if it has strengthened engineering planning education, has a greater amount of credit for major special studies, and professional engineer knowledge education rather than general knowledge education.

\section{Conclusion and suggestion}

Therefore, the following efforts should be made to improve Korean engineering education both quantitatively and qualitatively.

First, various efforts are required for engineering programs to attract the best students. The trend of avoiding science and engineering programs is a result of many combined reasons such as a decline in the social status of engineers, a lack of stability, and insufficient treatment.To attract outstanding students, the government should change its policies and industry should provide better working conditions and benefits for engineers in addition to the efforts of engineering colleges. Also, the academic world should play a role in determining how to revive engineering colleges. 
Second, it is important to improve the educational environment such as the curriculum, the teaching-learning method, method of evaluation, and facilities. According to "Research on improving education research easiness and academic-industry cooperation activation plan" conducted by the Ministry of Education and Human Resources Development, there are three big problems in Korean engineering education. First, "poor educational conditions and environment' including high ratio of student to instructors, a lack of experiment facilities and materials, too many lectures per instructor and a lack of teaching assistants. Second, "standardized lecture for mass production of skilled human capital and low quality education" including theory focused lectures, cramming education, standardized evaluation methods, instructor oriented curriculum, simple transfer of special knowledge, and lack of connection to industry that resulted in lack of actual site understanding. Third, a "lack of support on education facilities, administration and finances" including insufficient library facilities and engineering related books, lack of computer facilities, lack of university residences and welfare facilities, insufficient high speed internet connections required for information education, and lack of program oriented administration systems.

Third, an international level of engineering education and a stabilized engineering education accreditation system is necessary. The problems that Korean engineering education has are not only in Korean. They are problems that developed countries already have had in the past and they overcame those problems through engineering education accreditation which allowed them to have a global level of engineering education. To produce engineers with superior skils, one should have a high quality engineering education program. Korea should try to become an official member of Washington Accord and not just an associate member as in 2005.

Fourth, the system should be closely connected to society stakeholders to provide opportunities for students and to aid the accreditation system. Students should be encouraged and the accreditation system should be supported by companies that hire accredited graduates, the National Academy of Engineering of Korea, Korean Society for Engineering Education, National Engineering College Dean's Association, Engineering Society, industries, the Ministry of Education, and the Ministry of Commerce, Industry and Energy.

\section{Reference}

[1] The Ministry of Science and Technology (1995) The Almanac of Science and Technology

[2] High Council for Fundamental Change in Education (1995) New education reformation plan for establishing new education system that will lead globalized and information oriented society (I)

[3] Kim, Jong-chul (1990) A Study on Education Policy of Korea, Seoul: Gyo yuk gwa hak sa

[4] Lee, Byung-gi(1998) Educational revolution of Engineering College of Seoul National University, College of Engineering, Seoul National University

[5] The National Academy of Engineering of Korea (2004) A study on engineering education system for improving Korean engineering education

[6] Han, Song-yeop(2001) A study on variation plan for university education term and university administration, the Ministry of Education

\section{Biograhpy}

Sung-Gun Kang, a professor of Division of Advanced Materials Engineering and Science Hanyang University, Seoul Korea since 1981, President of Korean Society for Engineering Education from 2005 to 2006.

He received his bachelor of engineering in 1970 and his master of engineering in 1973 from Hanyang University .

He received his PhD degree from Stuttgart University in Germany in 1980. He worked as a director of R\&D program in Korea Science and Engineering Foundation for for 2 years (1999-2001). He was the President of Materials Research Society of Korea (2001-2002).He published 120 papers in the field of materials science and engineering.

Tae-Cheon Rho, a professor of the Technology Education Department at Chungnam National University since 1982, is the President of the Korean Institute of Industrial Educators and a chief editor of Journal of Engineering Education Research in the Korean Society for Engineering Education from 2003. He has received his bachelor of engineering and Master of education degrees from Seoul National University in 1973 and 1978 respectively, and Master and Doctor of literature degrees from The Academy of Korean Studies in 1990 and 2000 respectively. He worked at the Seoul Technical High School from 1973 to 1978 and has been a professor of Electrical Engineering Department in Daejeon Technical College from 1979 to 1982 . He majors in the Industrial \& Technology Education and the History of Korean Science \& Technology. 